\title{
La Realidad. Historia (breve) de un guionista cubano en Moscú
}

\author{
The Reality. (Brief) Story of a Cuban Screenwriter in Moscow
}

\begin{abstract}
ENRIQUUE PINEDA BARNET
Enrique Pineda Barnet (La Habana, 1933) fue guionista, junto con Evgenii Evtushenko, de la película Soy Cuba, dirigida por Serguéi Kalatózov en 1964, primer largometraje que surgió de la colaboración entre Cuba y la URSS. Esa labor le obligó a realizar diversas estancias en Moscú y vivir de cerca todo el proceso de ideación y documentación del filme. Como director, Pineda Barnet comenzó su trayectoria con Giselle, estrenada en 1963 y desde entonces ha dirigido una veintena de obras de ficción y documentales. Su película La bella del Alhambra, estrenada en 1989, convocó a más de dos millones de espectadores a las salas de cine en Cuba. Este último largometraje fue reconocido con diferentes distinciones, como el Premio Goya a la Mejor película extranjera de habla hispana en 1989. Enrique Pineda Barnet dirigió el que se considera el primer corto experimental cubano, Cosmorama (1964), que forma parte de la colección permanente en el Museo Nacional Centro de Arte Reina Sofía en Madrid. Paralelamente a su carrera cinematográfica, Pineda Barnet ha desarrollado una intensa carrera literaria, tanto narrativa y poética, como periodística.
\end{abstract}

\section{RELATO AuTOBIOGRÁFico}

RECIBIDO: 9 DE FEBRERO DE 2015

ACEPTADO: 3 DE JUNIO DE 2015

DOI: 10.7203/KAM.5.4603 


\section{Moscú, 1964}

Un guionista cinematográfico cubano trabaja el guión de una película difícil para una coproducción Cuba-URSS con un equipo de cineastas rusos de primera fila: Soy Cuba.

Enrique está solo en Moscú, aun no habla el idioma ruso, escasos cubanos u otros latinos merodean alrededor, entre ellos, de paso, Pablo Neruda y la cantante peruana Yma Sumak. No hay con quien intercambiar un saludo.

La habitación 417 del Hotel Moscú, junto a la Plaza Roja, es atendida por la mucama María Ivanna Kozlova. Anciana de limpios ojos azules y cabello perlado que ata en sobrio moño recogido. María Ivanna se presenta:

\section{-Iá, Mary Pickford.}

Y canta canciones de los Urales, baila danzas rusas frente a la cama de Enrique, lo hala por los pies

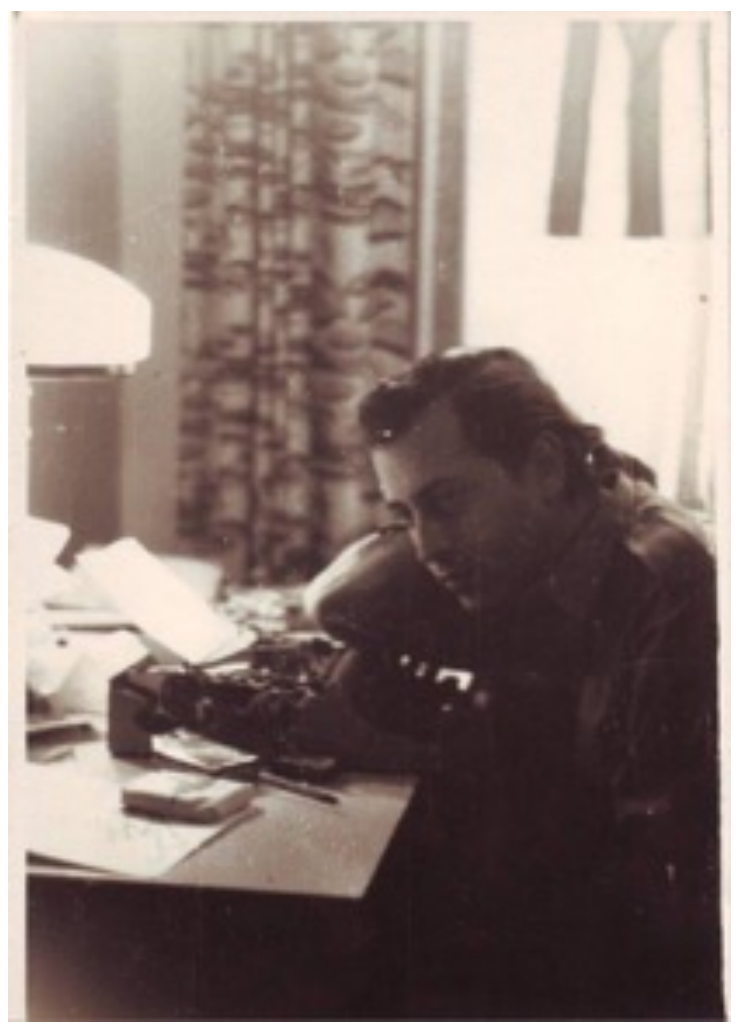
hasta la alfombra y le hace cosquillas como a un niño. Hoy esconde tras su espalda una manzana, mañana un trocito de caviar prensado, un dulce, cualquier golosina. Juega a un “¿Qué traigo aquí?” y todo es en ruso -porque es su única lengua- y alfabetiza al escritor con palabras rusas elementales.

Por las noches, al llegar a su "quartira", María Ivanna llama al joven cubano solitario para interesarse si tiene "temperatura". Y así, se va convirtiendo en la que fue para siempre "Mama María”.

Segis Álvarez, el joven españolito que sirve de intérprete a Enrique, hace testimonio del desarrollo de esta relación. A Segis le divierte. Segis es uno de aquellos niños españoles que fueron llevados a Moscú cuando la Guerra Civil en España, es el hijo de Segis Álvarez, la voz española de Radio Moscú. Segis hijo es trabajador de la fábrica de automóviles, y escasas veces consigue alguna contrata como intérprete de español. Su madre, Julita, hace casi veinte años conserva sus maletas sin vaciar, y no ha comprado refrigerador porque "en cualquier momento volvemos a la Patria...".

Segis acompaña a Enrique a una aventura: Mamá María lo ha invitado a visitar su "quartira", actividad penalizada para cualquier soviético, a los que les está prohibido relacionarse privadamente con extranjeros. La habitación de Mamá María es apenas un espacio en el que mal caben María Ivanna, y sus 
hijas Olga y Valia, telefonista y traductora de inglés respectivamente, ambas solteras, y el hijo de Olga. Un niño de unos 7 años, llamado Volodia. La mesa servida con pulcritud y esmero, ofrece manjares cuidadosamente reunidos para halagar a los visitantes. Todos están orgullosos del acontecimiento.

Enrique lleva del brazo a Mamá María al estreno de una de sus películas en un teatro de Moscú. Ella va feliz y campante.

El niño Volodia le pide a Enrique que sea su padrino en la imposición de su pañoleta de pionero, el próximo domingo, en un campamento en las afueras de Moscú. Le acompaña Segis para traducir los discursos.

El paseo por el campamento y sus instalaciones ocupa todo un hermoso domingo campestre. Volodia hace su juramento de pionero:

-Juro estudiar español para escribirle a mi tío Enrique.

Retenido en un álbum fotográfico, la última foto del álbum va sin pegar "para que no sea la foto final”.

\section{La Habana, 1987}

A la casa de Enrique llega una carta con un matasellos de Mozambique. Sorpresa:

Soy Volodia, como prometí, estudié español para escribirle a mi tío Enrique. Soy graduado en Letras Hispánicas, cumplo mi trabajo social en Mozambique y escribo en español las tradiciones de este país.

Una revista Bohemia de 1964, registra esta historia.

Enrique viajó ese año al Festival de Cine de Moscú. Volodia fue a recibirlo y lo llevó a su nuevo departamento con su madre y Mamá María, ya muy anciana encerrada en su habitación. Mamá María salió a recibir al visitante, descorcharon una botella para brindar con champagne y bailaron un vals.

Pasaron los años, la Perestroika, el muro de Berlín, había sido ya la caída de Franco en España. Se perdieron las comunicaciones.

\section{La Habana. Correo electrónico}

Enrique recibe en su ordenador un mensaje un tanto jeroglífico entre caracteres eslavos en lugar de los acentos y las eñes. 
Soy Volodia, tu sobrino de Moscú. Encontré en internet tu página web y tu dirección. Adjunto la foto de mi hijo Pavel, que estudia Derecho, habla español como su padre, y le escribimos con amor al tío Enrique.

\section{Epílogo}

Mamá María falleció en los 90.

Segis Álvarez con su familia regresó a España.

Volodia trabaja entre Moscú, Toledo y África.

Enrique celebra la resurrección exitosa de la película Soy Cuba-que fue un fracaso en el 64- con El Mamut Siberiano del joven brasilero Vicente Ferraz cuarenta años después.

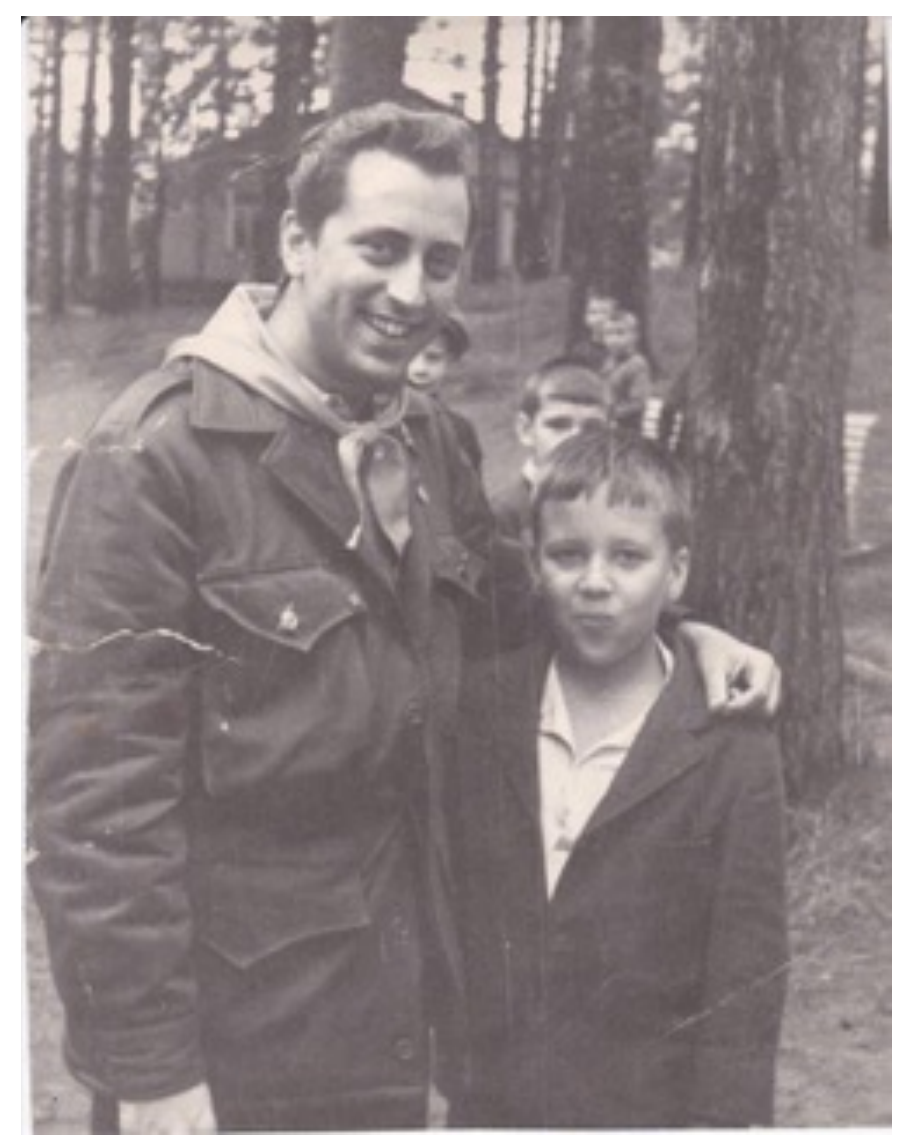

